\title{
Ocular motor and manual tracking in Parkinson's disease and the effect of treatment
}

\author{
J M GIBSON,* R PIMLOTT, $\uparrow$ C KENNARD \\ From the Department of Neurology The London Hospital, London, UK
}

SUMMARY A quantitative analysis of unpredictable saccadic and smooth pursuit ocular motor and manual tracking was performed in 15 mildly affected, previously untreated subjects suffering from Parkinson's disease and in age-matched normal controls. The patients' ocular saccades were characterised by an increased variability of their latencies and reduced accuracy, with normal velocity profiles apart from saccadic duration. Their smooth pursuit had a decreased velocity gain. Similar abnormalities were found with manual tracking. Clinical improvement with dopaminergic drugs was associated with an improvement of saccadic accuracy and smooth pursuit gain. It is postulated that the ocular motor changes seen in Parkinson's disease are contingent upon functional dopamine levels in the basal ganglia.

Impairment of eye movements has become an accepted clinical finding in patients with Parkinson's disease; the common abnormalities includes hypometric saccades and impaired smooth pursuit. ${ }^{1}$ In a qualitative study Corin $e t a l^{2}$ reported finding ocular motor abnormalities in three-quarters of their Parkinson's disease patients. Because of the relative accuracy and ease with which eye movements can be recorded and analysed, these findings offered the prospect of an objective measurement of akinesia in Parkinson's disease. In a quantitative study De Jong and Melville Jones ${ }^{3}$ referred to "akinesia, hypokinesia and bradykinesia in the oculomotor system", describing saccadic inaccuracy and variability of performance in Parkinson's disease. In subsequent publications, which have been confined to the horizontal gaze systems, no clear view has emerged regarding the exact nature of Parkinsonian ocular motor abnormalities. Mean saccadic latencies have been described as normal, but with wider variation, ${ }^{4}$ in response to a visual ${ }^{56}$ or auditory ${ }^{7}$ stimuli. The interval between the end of a hypometric saccade and a subsequent corrective saccade (intersaccadic

*Present address: Department of Neurology, Royal Victoria Hospital, Belfast, Northern Ireland. IInternational Management Operating Systems, Farrington Road, London.

Address for reprint requests: Dr C Kennard, The London Hospital, Whitechapel, London E1 1BB, UK.

Received 7 May 1986 and in revised form 23 October 1986 Accepted 5 December 1986 interval) has been reported as increased ${ }^{4}$ or normal. ${ }^{6}$ Regarding smooth pursuit performance, most authors simply state it to be "saccadic" or "cogwheel," but in a quantitative study De Jong and Melvill Jones ${ }^{8}$ found a reduced gain and impaired saccadic compensation, whilst White et $a l^{6}$ found a reduction in the "gain element".

Probable explanations for these differing views expressed in the literature include the use of patients within a study of varying disease severity, and with different forms of therapy. Centrally acting drugs of many types impair ocular motor function, ${ }^{9}$ whilst levodopa preparations may give rise to ocular motor dyskinesias. ${ }^{10}$

To date there are no quantitative ocular motor studies on mildly affected, untreated Parkinson's disease patients, and only one brief report on the effect of levodopa on eye movements in two patients with Parkinson's disease. ${ }^{11}$

One objection to isolated studies of ocular motor function in Parkinson's disease is the absence of information on how ocular motor abnormalities correlate with limb akinesia in the same subjects. Corin et $a l^{2}$ felt that there was a correlation between impaired ocular motor function and limb akinesia on clinical grounds, and Shibasaki et $\mathrm{al}^{7}$ included reaction time (RT) measurement in the limbs, but this measurement is probably insufficient to characterise akinesia. ${ }^{12}$ Manual tracking experiments have yielded much important data on motor control in normal subjects ${ }^{13-15}$ and Parkinson's disease. ${ }^{16-20}$ Using the same visual stimulus one can apply identical 
methods of analysis to limb and ocular movements. In an attempt to circumvent the objections to earlier purely ocular motor studies, and make observations relevant to somatic muscle akinesia we have studied horizontal saccadic and smooth pursuit tracking of the eye and hand separately in mildly affected, untreated, Parkinson's disease patients and have then examined the effects of drug therapy on these systems.

\section{Methods}

\section{Clinical}

Fifteen patients with a diagnosis of idiopathic Parkinson's disease, without evidence of dementia on clinical assessment, were studied (mean age 58 years, range 28-72). None was taking any drugs known to affect eye movements and none had received previous antiparkinsonian therapy (table 1). Fifteen age-matched normal subjects acted as controls (mean age 58 years, range $32-72$ ).

\section{Laboratory}

Subjects were seated in a modified dental chair in a darkened room, with their eyes level with a screen positioned at a distance of $150 \mathrm{~cm}$. The target was a red laser spot which was reflected off a mirror galvanometer, controlled by a microcomputer, onto a curved screen where it subtended $23^{\prime}$ of visual angle. Eye movements were recorded using the infrared limbus reflection technique. For hand tracking the subject controlled a white light spot which subtended $30^{\prime}$ of visual angle and could be superimposed upon the target spot. With the forearm comfortably supported, subjects held a light weight low-friction lever (manipulandum) between thumb and forefinger. A given angular displacement of the manipulandum would produce an identical angular movement of the tracking spot on the screen, and was accomplished by a combination of wrist flexion/extension and forearm pronation/supination movements.
Recording and analysis

Signals from target, eyes, and hand were recorded on a chart recorder and on FM analogue tape. Records were low-pass filtered at $500 \mathrm{~Hz}(-3 \mathrm{db})$ and then digitised at 1000 samples per second using a MINC PDP 11/23 computer. After digital filtering the bandwidth of the analysis was $300 \mathrm{~Hz}$ for position, and $90 \mathrm{~Hz}$ for velocity data. Digitised signals could be viewed at the terminal to allow rejection of artifacts such as blinks, and for the labelling of relevant sections for analysis.

The latency, duration, peak velocity, accuracy of the primary saccade and the intersaccadic interval were computed. Means and standard deviations of latency data were calculated. A straight line was then fitted to the duration/amplitude data to obtain the intercept (A value), slope (B value) and correlation coefficient $r$. An exponential equation of the form: Peak velocity = K(1-Exp (Lx saccade Amplitude)) was fitted to the peak velocity/saccade amplitude data to obtain the asymptote ( $\mathrm{K}$ value), and "roll-off point" (L value) and correlation coefficient. The percentage of all primary saccades falling within $\pm 10 \%$ of the target during the saccadic tests was used to define saccadic accuracy.

For smooth pursuit analysis saccades were eliminated on the basis of velocity. The remaining smooth pursuit was then analysed for velocity gain and position error. The velocity gain was calculated instantaneously as eye velocity over target velocity and the position error as eye position minus target position. These values were kept in a running average for target velocity values $0-4.99^{\circ} / \mathrm{s}, 5-9.99^{\circ} / 8,10-14.99^{\circ} / \mathrm{s}$ etc, up to a target velocity of $100^{\circ} / \mathrm{s}$. The statistic used for the comparison of groups was the figure for these functions at a target velocity of $50^{\circ} / \mathrm{s}$. (This point was taken as we were unable to find an adequate mathematical model to describe the entire range of smooth pursuit velocities). Data from the manual tracking tests was treated in a similar way except that saccadic rejection was not necessary for the smooth pursuit tracking.

A standard recording session consisted of: (a) Calibration

Table 1 Details of patients studied

\begin{tabular}{|c|c|c|c|c|c|c|c|c|}
\hline \multirow[b]{2}{*}{ No } & \multirow[b]{2}{*}{ Sex } & \multirow{2}{*}{$\begin{array}{l}\text { Age } \\
(y r)\end{array}$} & \multirow{2}{*}{$\begin{array}{l}\text { Duration of } \\
\text { illness (months) }\end{array}$} & \multicolumn{2}{|c|}{ Akinesia } & \multicolumn{2}{|c|}{ Modified Webster } & \multirow[b]{2}{*}{ Anti-Parkinsonian Drugs at end-point } \\
\hline & & & & $R$ & $L$ & Start & Finish & \\
\hline 1 & $\mathbf{M}$ & 49 & 10 & + & - & 70 & 28 (I) & \multirow{15}{*}{$\begin{array}{l}\text { Bromocriptine } 7.5 \mathrm{mgs} \\
\text { Benzhexol } 3 \mathrm{mgs} \\
\text { Madopar } 250 \times 5 \\
\text { Madopar } 250 \times 2 \\
\text { Madopar } 125 \times 1 \\
\text { Amantadine } 200 \mathrm{mgs} \\
\text { Bromocriptine } 25 \mathrm{mgs} \\
\text { Sinemet } 110 \times 3 \\
\text { Amantadine } 200 \mathrm{mgs} \\
\text { Bromocriptine } 15 \mathrm{mgs} \\
\text { Sinemet } 110 \times 3 \\
\text { Sinemet Plus } \times 5 \\
\text { Sinemet } 275 \times 3 \\
\text { Sinemet Plus } \times 3 \\
\text { Benzhexol } 3 \mathrm{mgs} \\
\text { Bromocriptine } 18.375 \mathrm{mgs} \\
\text { Madopar } 125 \times 8 \\
\text { Madopar } 125 \times 3 \\
\text { Madopar } 250 \times 3 \\
\text { Benzhexol } 3 \mathrm{mgs}\end{array}$} \\
\hline 2 & $\mathbf{M}$ & 62 & 24 & + & ++ & 79 & 36 (I) & \\
\hline 3 & $\mathrm{~F}$ & 66 & 18 & + & - & 75 & 33 (I) & \\
\hline 4 & $\mathbf{F}$ & 55 & 24 & ++ & - & 58 & $28(I)$ & \\
\hline 5 & $\mathbf{M}$ & 49 & 12 & - & $+t$ & 59 & 68 (NI) & \\
\hline 6 & $\mathbf{F}$ & 72 & 12 & + & ++ & 113 & 52 (I) & \\
\hline 7 & $\mathbf{F}$ & 64 & 36 & + & - & 100 & 90 (NI) & \\
\hline 8 & $\mathbf{M}$ & 72 & 96 & $+t$ & ++ & 182 & 116 (I) & \\
\hline 9 & $\mathrm{~F}$ & 65 & 12 & $+t$ & - & 87 & 45 (I) & \\
\hline 10 & $\mathbf{F}$ & 49 & 18 & - & ++ & 91 & 88 (NI) & \\
\hline 11 & $M$ & 69 & 48 & + & - & 67 & 38 (I) & \\
\hline 12 & $\mathbf{M}$ & 58 & 36 & + & - & 72 & 84 (NI) & \\
\hline 13 & $\mathbf{M}$ & 63 & 12 & + & $+t$ & 100 & 72 (NI) & \\
\hline 14 & $\mathbf{M}$ & 28 & 28 & $+t$ & - & 72 & 72 (NI) & \\
\hline 15 & $\mathrm{~F}$ & 50 & 12 & + & + & 64 & 64 (NI) & \\
\hline
\end{tabular}

(Key; - absent, + mild, ++ moderate, +++ severe; $\mathbf{I}=$ Improved, NI = Not improved) 
(b) Eye saccade test: two runs of $\mathbf{4 0}$ random steps (timing varied between $0.8-1.5 \mathrm{~s}$, and amplitude between nine possible positions, $15^{\circ}, 12.25^{\circ}, 7 \cdot 5^{\circ}, 3 \cdot 75^{\circ}$, to left and right of centre. (c) Eye smooth pursuit test: the target moved in a horizontal sinusoidal pattern, peak to peak amplitude $30^{\circ}$, at nine different frequencies (range $0.05-0.8 \mathrm{~Hz}$ ). Each frequency, randomly chosen, was used for between 0.8-1.5 s and then changed to a different frequency for the same period and changed in this way repeatedly for 60 seconds. In this way the target moved at each frequency for periods of $0.8-1.5 \mathrm{~s}$ on several separate occasions during the test. Subjects were instructed to watch the target as closely as possible. (d) Hand "saccadic" tracking (each hand tested separately) stimulus as (b) above, except that the time between target steps was increased to $1.5-3 \mathrm{sec}$. (e) Hand "smooth pursuit" tracking (each hand tested separately), stimulus as (c) above. Subjects were instructed to closely follow the target and keep their own tracking spot superimposed on the target as accurately as possible. They were given a practice session prior to the recordings.

\section{Experiment (a)}

The above tests were administered to the untreated patients and normal controls, after clinical rating with the Hoehn and $\mathrm{Yahr}^{21}$ Northwestern Disability, ${ }^{22}$ and the Webster scale $^{\mathbf{2 3}}$ (the last of these had weighting applied to functionally important aspects, for example bradykinesia and gait).

\section{Experiment (b)}

All the patients studied in (a) were then followed up on therapy at three weekly intervals when the tests and clinical rating was repeated. Therapy consisted of either a rapid or slow incremental dosage regime of bromocriptine, or of levodopa with a dopa-decarboxylase inhibitor, Sinemet or Madopar. The end-point for each patient was attained when either the weighted Webster rating had improved by a minimum of $33 \%$ (clinically improved group), or had not improved at the time the last recording was made six months after treatment was commenced (non-improved group). Non-parametric analysis using the Wilcoxon matched-pairs signed-ranks test was performed.

\section{Results}

(a) Untreated Parkinson's disease patients vs normal controls

Inspection of chart records did not show gross differences in the ocular motor function between the two groups, although with manual tracking patients with Parkinson's disease showed slowed movements and poor sinusoidal tracking. Quantitative analysis of eye saccades (table 2) showed no significant prolongation of mean latencies or mean intersaccadic intervals, but the standard deviations of both these measurements were significantly increased in Parkinson's disease $(p<0.01)$. Saccadic accuracy was significantly reduced in Parkinson's disease ( 27 vs $35 \%, p<0.05$ ). The peak velocity $K$ and $L$ values showed no significant difference, but duration $B$ values (slope) were greater in Parkinson's disease $(0.37 \pm 0.007$ vs $0.35 \pm 0.005, p<0.05)$. For both duration and peak velocity models, $r$ values were high $(0.88-0.91)$, indicating that these were valid. An example of the saccadic data from one patient is shown in fig 1 .

Eye smooth pursuit velocity gain was significantly reduced in the patients $(0.41$ vs $0.52, \mathrm{p}<0.05)$. The position error showed no significant difference. An example of the smooth pursuit data from one patient is shown in figs 2 and 3.

In the manual hand tracking experiments the subjects satisfactorily tracked the target with their eyes, but the influence of hand movements on eye movements was not determined by computer analysis. All hand tracking data is taken from the clinically more affected hand. The hand "saccadic" tests showed signficant impairments in mean latency and their standard deviations, duration B value, and peak velocity $L$ value (table 2 ). Hand smooth pursuit gain was significantly reduced in patients with $P D(0.28$ vs

Table 2 Ocular motor and manual tracking performance in untreated Parkinson disease vs controls (means and standard deviations)

\begin{tabular}{|c|c|c|c|c|c|c|}
\hline & \multicolumn{3}{|l|}{ Eye } & \multicolumn{3}{|l|}{ Manual } \\
\hline & Parkinson's & Control & $p$ value & Parkinson's & Control & $p$ value \\
\hline \multicolumn{7}{|l|}{$S A C C A D E S$} \\
\hline $\begin{array}{l}\text { Latency Mean (ms) } \\
\text { Standard deviation }\end{array}$ & $\begin{array}{r}207(32) \\
73(20)\end{array}$ & $\begin{array}{r}188(21) \\
53(16)\end{array}$ & $\begin{array}{l}\text { NS } \\
<0.01\end{array}$ & $\begin{array}{r}354(55) \\
81(11)\end{array}$ & $\begin{array}{r}300(40) \\
65(14)\end{array}$ & $\begin{array}{l}<0.01 \\
<0.01\end{array}$ \\
\hline \multicolumn{7}{|l|}{ Intersaccadic interval } \\
\hline $\begin{array}{l}\text { Mean (ms) } \\
\text { Standard deviation }\end{array}$ & $162(26)$ & $165(36)$ & NS & - & - & - \\
\hline $\begin{array}{l}\text { Standard deviation } \\
\text { Peak velocity }\end{array}$ & $126(23)$ & 104 (15) & $<0.01$ & - & - & - \\
\hline $\begin{array}{l}\mathrm{K} \text { value } \\
\mathrm{L} \text { value }\end{array}$ & $\begin{array}{l}770(87) \\
16 \cdot 7(2 \cdot 3)\end{array}$ & $\begin{array}{c}792(116) \\
17 \cdot 3(2 \cdot 7)\end{array}$ & $\begin{array}{l}\text { NS } \\
\text { NS }\end{array}$ & $\begin{array}{r}213(53) \\
21(3 \cdot 3)\end{array}$ & $\begin{array}{r}235(55) \\
18(3 \cdot 2)\end{array}$ & $\begin{array}{l}\text { NS } \\
<0.01\end{array}$ \\
\hline \multicolumn{7}{|l|}{ Duration } \\
\hline $\begin{array}{l}\text { A value } \\
\text { B valiue }\end{array}$ & $\begin{array}{l}3.69(0.07) \\
0.37(0.007)\end{array}$ & $\begin{array}{l}3.71(0.06) \\
0.35(0.05)\end{array}$ & $\begin{array}{l}\text { NS } \\
<0.05\end{array}$ & $\begin{array}{l}4.88(0.25) \\
0.77(0.01)\end{array}$ & $\begin{array}{l}4.81(0.17) \\
0.50(0.02)\end{array}$ & $\begin{array}{l}\text { NS } \\
<0.05\end{array}$ \\
\hline Accuracy (\%) & $27(10)$ & $35(8)$ & $<0.05$ & - & - & - \\
\hline \multicolumn{4}{|l|}{ SMOOTH PURSUIT (at $50^{\circ} / \mathrm{s}$ ) } & $0.28(0.23)$ & $0.73(0.22)$ & $<0.01$ \\
\hline Position error (deg) & $1.67(0.57)$ & $1.83(0.66)$ & NS & $4 \cdot 87(2 \cdot 15)$ & $3.95(1.29)$ & NS \\
\hline
\end{tabular}

- = test not applicable. 

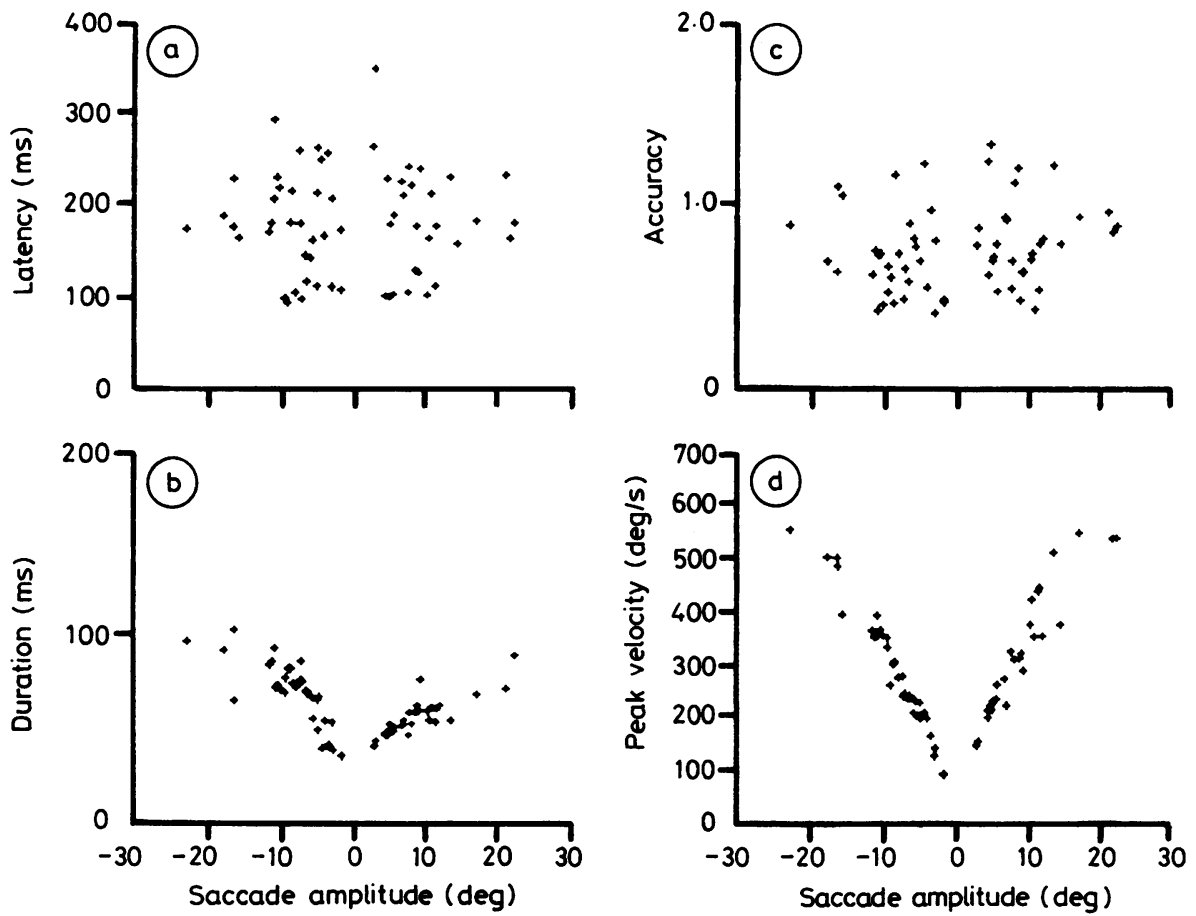

Fig 1 An example of the saccadic data from a patient with Parkinson's disease. The saccade amplitude in degrees is plotted along the abscissa, negative values being saccades directed to the left and positive values to the right. The saccade amplitude is plotted against saccade, (A) latency (ms), (B) duration (ms), (C) accuracy (saccade amplitude-target amplitude), (D) peak velocity ( $\%$ s).

$0.73, \mathrm{p}<0.01)$ whilst position error was not.

Eye/hand correlations Where appropriate, correlation coefficients for eye and hand performance were calculated using the Spearman rank test. Positive correlations were found, but these were only statistically significant for latency $(r=0.6633, \mathrm{p}<0.01)$ and smooth pursuit gain $(\mathrm{r}=0.5536, \mathrm{p}<0.05)$.

Unilateral Parkinson's disease

Nine of the group of 15 untreated PD patients had clinically unilateral disease. This provided the opportunity to look for asymmetries in ocular motor performance towards and away from the clinically affected sides (see table 3 ). There were only minor differences in saccades and smooth pursuit, which were not statistically significant.

The hand tracking data from these same patients (table 3 ) shows highly significant differences between the two sides, whereas the non-affected sides show no significant difference from normal controls except for the duration B-value.

\section{(b) Changes with therapy}

When the final measurements were taken, eight patients were clinically improved and seven were not (table 1). This rather high proportion of nonimproved patients at the end of the period of study was largely due to patients who were started on a slow incremental dosage regime of bromocriptine, and who subsequently had to be changed to levodopa towards the end of the 6 month period. Retrospective analysis of the clinical data showed no differences between the two groups (responders and nonresponders) prior to therapy. In the clinically nonimproved group no statistically significant changes in eye saccadic or smooth pursuit tracking occurred with treatment (table 4). In the clinically improved group, there was a reduction in the mean latencies and their standard deviations which did not reach significance, but eye accuracy significantly improved $(29$ to $40 \%, p<0.05)$. Eye durations showed no changes, but the peak velocity $L$ values improved 


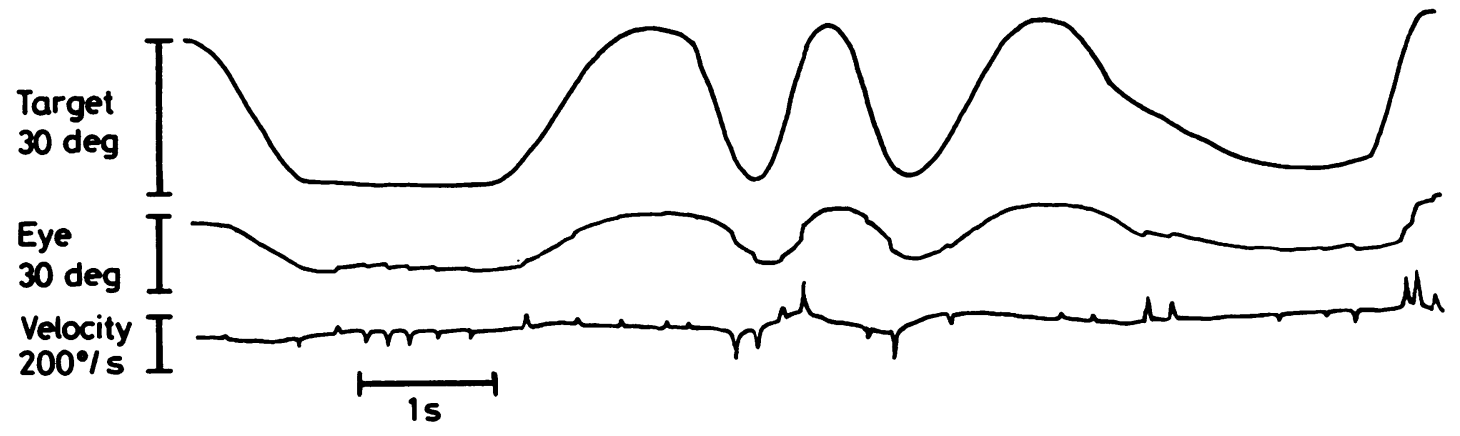

Fig 2 A representative example of eye movement smooth pursuit tracking in a Parkinsonian patient.

$(17 \cdot 1$ to $19 \cdot 8, \mathrm{p}<0 \cdot 05)$. Eye smooth pursuit gain showed a highly significant increase in this group $(0.41$ to $0.54, \mathrm{p}<0.01)$. The position error showed an unexpected increase $(1.59$ to 2.09 deg., $p<0.05)$.

Analysis of hand tracking data failed to show any significant improvement in the "saccadic" tests for either the improved or non-improved group, but the hand smooth pursuit velocity gain did increase significantly $(0.24$ to $0.55, \mathrm{p}<0.01)$ in the former group (table 5).

\section{Discussion}

In this study we have shown that "akinesia" (by which is implied a variety of problems involving the execution of voluntary movements) ${ }^{24}$ is present in the ocular motor system of patients with mild untreated Parkinson's disease, and some improvement in ocular motor function does occur with dopaminergic treatment. In the eye saccadic system, abnormalities were found in the untreated patients, namely slightly prolonged mean latencies which however did not reach significance, but significantly increased saccadic latency variability, and saccadic inaccuracy. In contrast to previous reports where mean saccadic velocities for saccades of arbitrary sizes were reported, we have used models which give a more complete picture of saccadic performance over a $30^{\circ}$ range. This encompasses the vast majority of naturally occurring saccades $^{25}$ and makes better use of the available data. ${ }^{2627}$ We found prolongation of saccadic duration, which was not due to inclusion of glissades, with normal peak velocities in the untreated patients. This is an interesting finding which could either be explained by an inability of the saccadic burst neurons, in the paramedian pontine reticular formation, to fire synchronously during the saccade, or by a failure of the burst neurons to maintain an appropriate high rate of discharge. Melvill Jones and De Jong ${ }^{4}$ found an increased intersaccadic interval in their
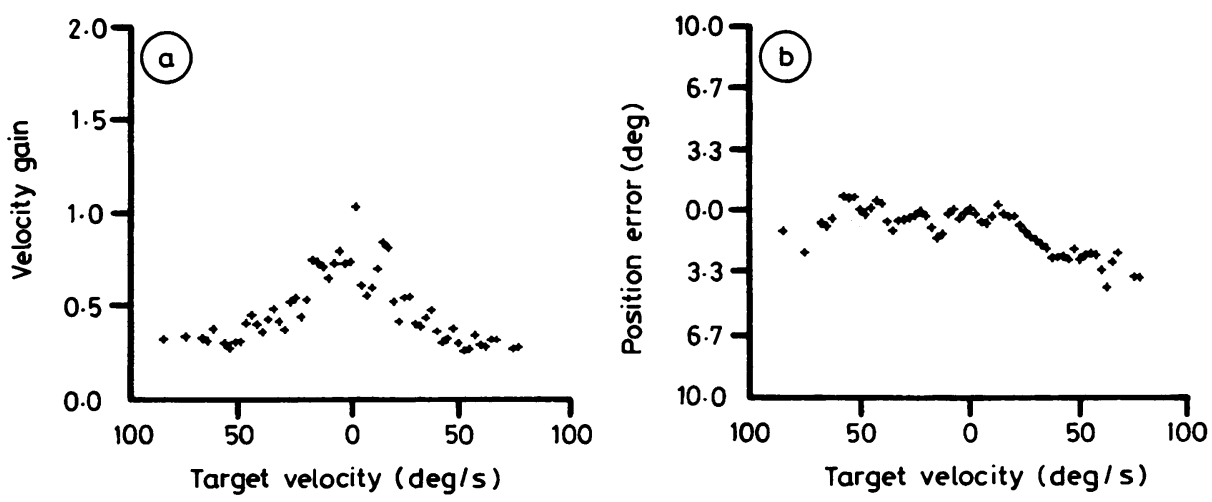

Fig 3 An example of the smooth pursuit data from a patient with Parkinson's disease. The target velocity in $\%$ is plotted along the abscissa, values to the left and right of 0 being target moving to the left and right respectively. The target velocity is plotted against the smooth pursuit, $(A)$ mean velocity gain, and ( $B$ ) mean position error (degrees). 
Table 3 Saccadic and smooth pursuit ocular and manual metrics towards affected and non-affected sides in unilateral PD cases (untreated $n=9$ ) (mean and standard deviations)

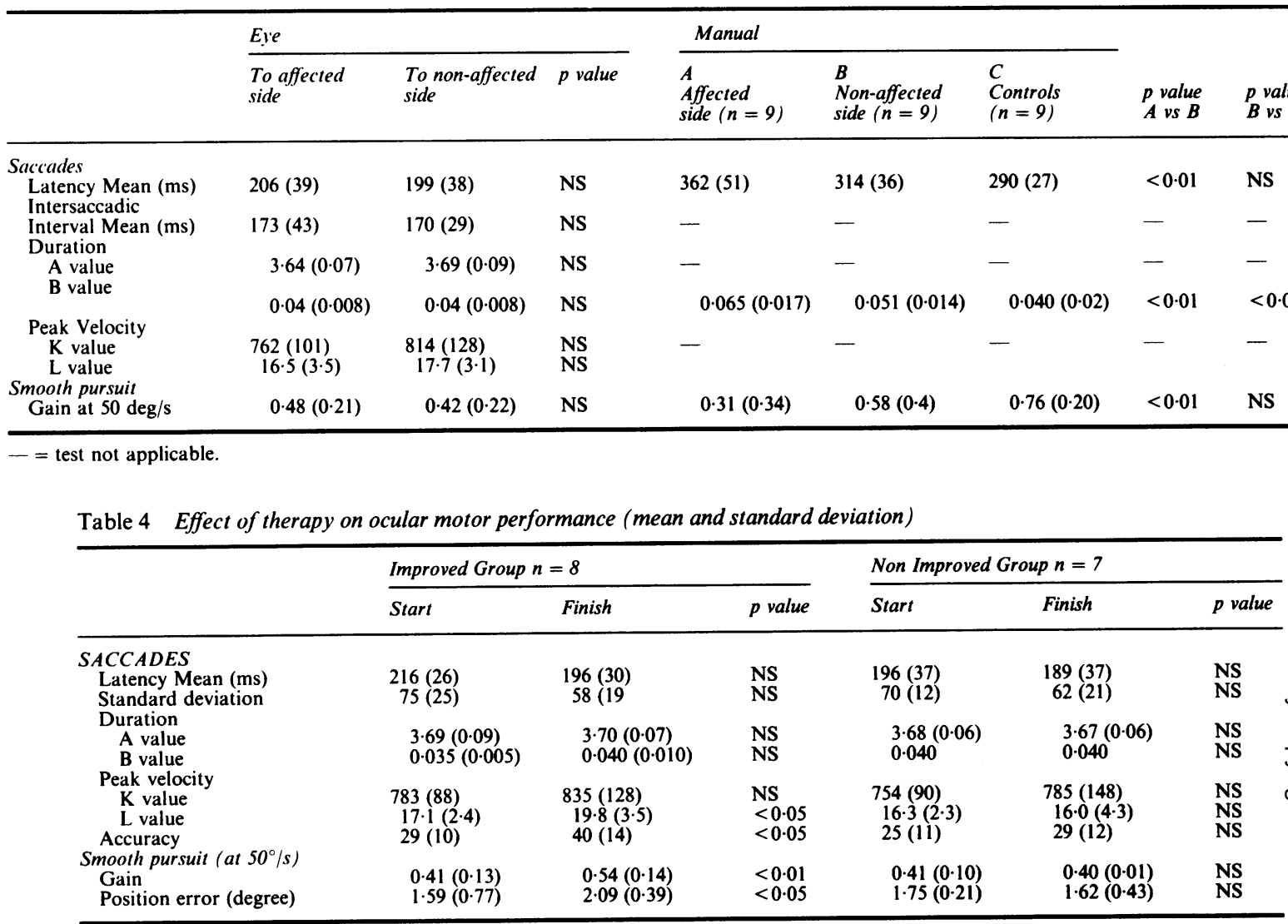

patients using a slightly different experimental paradigm, implying delays in error correction for the eye, analagous to those found in limbs, ${ }^{28}$ whilst we concur with White $e t a^{6}$ who found normal error correction in the eye. The various abnormalities that we found indicate that PD patients have a variable difficulty in initiating saccades, which are often hypometric, but which reach almost normal peak velocities. In a study of more severely affected Parkinson's disease patients exhibiting the "on-off" phenomenon, we found in some patients ${ }^{29}$ slow saccades of prolonged duration and reduced peak velocity.

The manual tracking findings for the "saccadic" tasks were comparable to those for the eye in terms of latencies and variability of performance. Movement time slowing however, was a prominent factor in the limbs, which was not apparent in the eye. The hand movements required in our experiments were small, and so patients and normal subjects alike tended to overshoot the target, and this overshoot was more marked in the normal subjects who could generate faster ballistic movements. Such contrasting strategies of movements have been previously reported. ${ }^{18}$

With regard to the eye smooth pursuit system, our method of analysis of the smooth pursuit gain does average the gains obtained for a particular target velocity when the target was moving at different frequencies. Since pursuit gain is dependent to a certain extent on target acceleration ${ }^{30}$ the fall off of gain at the higher target velocities may be due to a fall off with frequency since only the higher target frequencies used would generate these high target velocities. Despite this factor there was a significant reduction in pursuit gain in Parkinson's disease patients at the target velocity used for comparison $\left(50^{\circ} / \mathrm{s}\right)$ with no increase in position error. Our findings are therefore in agreement with the two previous quantitative studies of smooth pursuit in Parkinson's disease. ${ }^{68}$ Our manual smooth pursuit findings were closely comparable to those for the eyes, showing no 
Table 5 Effect of therapy on hand tracking performance (mean and standard deviations)

\begin{tabular}{|c|c|c|c|c|c|c|}
\hline & \multicolumn{3}{|c|}{ Improved Group $n=8$} & \multicolumn{3}{|c|}{ Non Improved Group $n=7$} \\
\hline & Start & Finish & p value & Start & Finish & $p$ value \\
\hline \multicolumn{7}{|l|}{$S A C C A D E S$} \\
\hline $\begin{array}{l}\text { Latency Mean (ms) } \\
\text { Duration }\end{array}$ & $368(58)$ & $333(51)$ & NS & $339(50)$ & $333(34)$ & NS \\
\hline $\begin{array}{l}\text { Duration } \\
\text { A value } \\
\text { B value }\end{array}$ & $\begin{array}{l}4.98(0.25) \\
0.065(0.01)\end{array}$ & $\begin{array}{l}4.94(0.20) \\
0.060(0.008)\end{array}$ & $\begin{array}{l}\text { NS } \\
\text { NS }\end{array}$ & $\begin{array}{l}4.76(0.20) \\
0.070(0.03)\end{array}$ & $\begin{array}{l}4.84(0.22) \\
0.071(0.028)\end{array}$ & $\begin{array}{l}\text { NS } \\
\text { NS }\end{array}$ \\
\hline $\begin{array}{l}\text { Peak velocity } \\
\text { L value } \\
\text { Smooth pursuit }\left(\text { at } 50^{\circ} / \mathrm{s}\right)\end{array}$ & $21(4)$ & $20(5)$ & NS & $21(2)$ & $16(7)$ & NS \\
\hline $\begin{array}{l}\text { Gain } \\
\text { Position error (degree) }\end{array}$ & $\begin{array}{l}0.24(0.19) \\
5 \cdot 18(2.0)\end{array}$ & $\begin{array}{l}0.55(0.21) \\
4.57(1.5)\end{array}$ & $\begin{array}{l}<0.01 \\
\text { NS }\end{array}$ & $\begin{array}{l}0.32(0.29) \\
4.53(2 \cdot 38)\end{array}$ & $\begin{array}{l}0.24(0.27) \\
3.66(1.5)\end{array}$ & $\begin{array}{l}\text { NS } \\
\text { NS }\end{array}$ \\
\hline
\end{tabular}

significant increase in lag, but impaired pursuit gain. Although we have found significant improvement in Parkinson's disease as a result of dopaminergic therapy, caution is necessary as any test of voluntary motor function used repeatedly may be subject to a learning effect despite the use of random stimuli. It has been stated that patients with PD do not learn compared with normals on manual tracking tasks $^{18{ }^{30}}$ but mildly affected patients might, and the effect of practice on ocular motor function is unknown. In a control study we found that repeated daily testing of six young normal subjects for $\mathbf{4}$ days, resulted in a significant learning effect on the latency (decreased) and peak velocity (increased) of eye saccades (unpublished observations). Saccadic accuracies showed great variability within individual subjects. The velocity gain of the smooth pursuit system of both the eye and hand showed remarkable constancy with no such learning effect. In the light of these observations the effect of treatment on saccadic functions must be treated with some reserve, although we found no evidence for a learning effect in the clinically non-improved group who showed no significant changes at the end of the study period after identical repeated testing to the improved group.

Our previous findings ${ }^{29}$ that comparable changes in saccadic function occur in patients with "on-off" phenomena during the "off" phase, which improve when "on", lends further support to the view that these saccadic deficits may be due to dopamine deficiency in the striatum.

Hikosaka and Wurtz ${ }^{32} 33$ were able to produce hypometric saccades in the monkey by injecting the GABAmimetic agent muscimol into the superior colliculus which is a structure known to be important in the generation of saccades. On the basis of these studies and earlier work ${ }^{34-36}$ it appears that the substantia nigra, pars reticulata tonically inhibits the superior colliculus via a GABAminergic pathway. Prior to a saccade to a visual target there is a reduction in this tonic inhibition. The striatum has an output to this part of the substantia nigra, and it is postulated that striatal dopamine deficiency causes defective disinhibition in the nigro-collicular pathway prior to saccades. Our finding of partly reversible saccadic deficits dependent on dopaminergic status is consistent with this hypothesis.

Ocular motor function in each horizontal direction is under unilateral cortical control. ${ }^{37}$ In our patients with unilateral limb akinesia, comparison of ocular motor function towards and away from the affected limb showed no asymmetries. However, in three subjects with unilateral Parkinson's disease Carl and Wurtz ${ }^{38}$ using a different saccadic task, found abnormalities of saccades to a remembered target made towards the affected limb.

We do not suggest that the ocular motor findings described in this paper are specific to Parkinson's disease. It does appear however, that measurement of eye movements, in particular the smooth pursuit gain, is a sensitive indicator of functional dopaminergic status, and may possibly be used in the future to obtain information on the pharmacodynamic profiles of antiparkinsonian drugs.

We are grateful to Mrs. Pat Stafford for secretarial help, and to Sandoz Pharmaceuticals for their support.

\section{References}

1 Miller NR. Walsh and Hoyt's Clinical Neuroophtholmology. 4th ed, vol 2, Baltimore, Williams \& Wilkins, 1985, 733-6.

2 Corin MS, Elizan TS, Bender MB. Oculomotor dysfunction in patients with Parkinson's disease. $J$ Neurol Sci 1972;15:251-65.

3 De Jong JD, Melvill Jones G. Akinesia, hypokinesia, and bradykinesia in the oculomotor system of patients with Parkinson's disease. Exp Neurol 1971;32:58-68.

4 Melvill Jones G, De Jong JD. Dynamic characteristics of saccadic eye movements in Parkinson's disease. Exp Neurol 1971;31:17-31.

5 Kennard C, Zangemeister WH, Mellors S, Stark L, Hoyt WF. Eye-head coordination in Parkinson's disease. In: 
Lennerstrand G, Zee DS, Keller EL (eds): Functional Basis of Ocular Motility Disorder. Oxford, Pergamon Press, 1982:517-20.

6 White OB, Saint-Cyr JA, Tomlinson D, Sharpe JA. ocular motor deficits in Parkinson's disease: II. Control of the saccadic and smooth pursuit systems. Brain 1983;106:571-87.

7 Shibasaki H, Sadatoshi T, Kuroiwa Y. Oculomotor abnormalities in Parkinson's disease. Arch Neurol 1979;36:360-4.

8 Melvill Jones G, De Jong J. Visual tracking of sinusoidal target movement in Parkinson's disease. DRB Aviat Med Res Unit Reports:no DR 225 1976:271-87.

9 Leigh RJ, Zee DS. The Neurology of Eye Movement. Philadelphia, FA Davis, 1983.

10 Shimizu N, Cohen B, Bala SP, Meridoza M, Yahr MD. ocular dyskinesias in patients with Parkinson's disease treated with levodopa. Ann Neurol 1977;1:167-71.

11 Highstein S, Cohen B, Mones R. Changes in saccadic eye movements of patients with Parkinson's disease before and after treatment with L-Dopa. Trans Am neurol Assoc 1969;94:277-9.

12 Evarts EV, Teravainen H, Calne DB. Reaction Time in Parkinson's Disease. Brain 1981;104:167-86.

13 Craik KJW. Theory of the human operator in control systems: I. The operator as an engineering system. $\mathrm{Br}$ J Psychol 1947;38:58-61.

14 Craik KJW. Theory of the human operator in control systems: II. Man as an element in a control system. $\mathrm{Br}$ J Psychol 1948;38:142-8.

15 Johns RJ, Draper IT. The control of movement in normal subjects. Bull Johns Hopkins Hosp 1964;115:447-64.

16 Cassel K, Shaw K, Stern G. A computerised tracking technique for the assessment of Parkinsonian disabilities. Brain 1073;96:815-26.

17 Flowers KA. Ballistic and corrective movements on an aiming task. Neurology 1975;25:413-21.

18 Flowers KA. Visual "Closed-Loop" and "Open-Loop" Characteristics of voluntary movement in patients with Parkinsonism and intention tremor. Brain 1976;99:269-310.

19 Flowers KA. Lack of prediction in the motor behaviour of Parkinsonism. Brain 1979;101:35-52.

20 Bloxham CA, Mindel TA, Frith CD. Initiation and execution of predictable and unpredictable movements in Parkinson's disease. Brain 1984;107:371-84.

21 Hoehn MM, Yahr MD. Parkinsonism: onset, progression and mortality. Neurology 1967;17:427-42.

22 Canter CJ, de la Torre R, Mier M. A method of evaluating disability in patients with Parkinson's disease. $J$ Neurol Mental Dis 1961;133:143-7.

23 Webster DD. Critical analysis of disability in Parkin- son's Disease. Mod Treat 1968;5:257-82.

24 Ad Hoc Committee WFN. The classification of extrapyramidal disorders $J$ Neurol Sci 1981;51:311-27.

25 Bahill AT, Adler D, Stark L. Most naturally occurring human saccades have magnitudes of 15 degrees or less. Invest Opthalmol 1975;14:468-9.

26 Bahill AT, Clark MR, Stark L. The main sequence, a tool for studying human eye movements. Math Biosci 1975;24:191-204.

27 Bahill AT, Brockenbrough A, Troost BT. Variability and development of a normative data base for saccadic eye movements. Invest Opthalmol Vis Sci 1981;21:116-25.

28 Angel RW, Higgins JR. Correction of false moves in pursuit tracking. J Exp Psychol 1969; 82:185-7.

29 Gibson JM, Kennard C. A quantitative study of "Onoff' fluctuations in the ocular motor system in Parkinson's disease. In: Yahr M, Bergmann J, eds. Advances in Neurology Vol 45 New York, Raven Press 1987:329-33.

30 Lisberger SG, Evinger C, Johanson GW, Fuchs AF. Relationship between eye acceleration and retinal image velocity during foveal smooth pursuit in man and monkey. J Neurophysiol 1981;46:229-49.

31 Draper IT, Johns RJ. The disordered movement in Parkinsonism and the effect of drug treatment. Bull Johns Hopkins Hosp 1964;115:465-80.

32 Hikosaka O, Wurtz RH. Modification of saccadic eye movements by GABA related substances I. Effect of muscimol and bicuculline in monkey superior colliculus. J neurophysiol 1985;53:266-91.

33 Hikosaka O, Wurtz RH. Modification of saccadic eye movements by GABA related substances II. Effect of muscimol in monkey substantia nigra pars reticulata. J Neurophysiol 1985;53:292-308.

34 Hikosaka O, Wurtz RH. Visual and oculomotor functions of monkey substantia nigra pars reticulata. 1. Relation of visual and auditory responses to saccades. $J$ Neurophysiol 1983;49:1230-53.

35 Hikosaka O, Wurtz RH. Visual and oculomotor functions of monkey substantia nigra pars reticulata. III. Memory-contingent visual and saccade responses. $J$ Neurophysiol 1983;49:1268-84.

36 Hikosaka O, Wurtz RH. Visual and oculomotor functions of monkey substantia nigra pars reticulata. IV. Relation of substantia nigra to superior colliculus. $J$ Neurophysiol 1983;49:1285-301.

37 Bender MB. Brain control of vertical and horizontal eye movements. Brain 1980;103:26-69.

38 Carl JR, Wurtz RH. Asymmetry of saccadic control in patients with hemi-Parkinson's disease. Association for Research in Vision and Ophthalmology. 1985; Abstracts p. 258 . 